\title{
Myeloblastic Leukemia with Massive Neoplastic Infiltration of the Skin and Mediastinum in a Cow
}

\author{
Takashi TAKAHASHI, Atsuko HAGIWARA, Kazuhiko EZURA ${ }^{1)}$, Tomoyuki SHIBAHARA ${ }^{2)}$ and Koichi KADOTA ${ }^{2)}$ \\ Tochigi Prefectural Animal Hygiene Laboratory, Hiraide Kogyo-Danchi, Utsunomiya 321-0905, ')Ezura Veterinary Hospital, 1-1632- \\ 5 Fujimi, Otawara, Tochigi 324-0028 and ${ }^{21}$ Hokkaido Research Station, National Institute of Animal Health, Sapporo 062-0045, Japan
}

(Received 10 August 1999/Accepted 16 December 1999)

ABSTRACT. An acute myeloblastic leukemia was found in a 3.5-year-old Holstein cow. The neoplasm was characterized by massive tumor growths, and there were multiple tumor nodules in the dermis or subcutis and a large tumor mass in the mediastinum. This tumor showed negative reactivity for CD3, CD79a, major histocompatibility complex class II and myeloid/histiocyte antigen. Ultrastructural features such as dispersed cytoplasmic granules and poorly developed organelles were compatible with those of early promyelocytes.—KEY wORDS: bovine, myeloblastic leukemia, skin.

There were many reports of malignant hematopoietic neoplasms in cattle, and the great majority dealt with lymphoid neoplasms, most of which were categorized into 4 clinicopathological types [20]. The immunophenotypes of these lymphomas have been investigated by means of flow cytometry or immunohistochemistry on frozen sections $[15,18]$. Other hematopoietic tumors were rare, but included follicular lymphoma [8], myeloblastic leukemia [17], monocytic leukemia [10], mast cell leukemia [21] and acute erythremic myelosis [24]. Here we describe a bovine myeloblastic leukemia, which was distinguishable from lymphoid neoplasms by immunohistochemical and ultrastructural examinations.

A 3.5-year-old Holstein cow showed anorexia and had multiple, raised skin nodules on the area ranging from the root of tail to the groin. Three days later, they increased in size, and other multiple nodules appeared over the neck and trunk. Nine days after the onset of clinical signs, the nodules were 2 to $10 \mathrm{~cm}$ in diameter, and were approximately 400 in number (Fig. 1). There were no scabs on their surfaces, and hair loss was undetectable. The superficial lymph nodes were enlarged, and a preliminary diagnosis of cutaneous leukosis was made. Because of the poor prognosis, the cow was euthanized. Just before death, blood examination showed leucocytosis (white blood cell count, 44,700/ $\mu l$ ), but the red blood cell count was $5380,000 / \mu l$, and the hematocrit was $29.6 \%$. On smears of peripheral blood, $55 \%$ of the leucocytes were lymphocytes, and $44 \%$ were immature mononuclear cells. Blood chemistry tests showed a markedly elevated value of lactate dehydrogenase $(12,250$ $\mathrm{IU} / l$ ). Antibodies to bovine leukemia virus (BLV) were not detected by the agar gel immunodiffusion test.

At necropsy, many tumor nodules were located in the subcutis alone, but some were in the dermis with or without involvement of the subcutis. On cross-section the tumors were homogeneous and milky white, being well demarcated from surrounding tissue though not encapsulated. Numerous similar nodules were present in the musculature of the thigh and buttock, and the majority were situated near the subcutis. Subcutaneous edema was found in the brisket, and a tumor mass, $20 \mathrm{~cm}$ in diameter, in which the trachea was embedded, was present in the area ranging from the precardial region of the thorax to the cervical region. There were multiple tumor nodules in the kidneys and mammary glands, and some nodules in the heart, liver, and gall bladder, and in the pulmonary subpleural and ruminal subserosal sites. Several tumor nodules were attached to the cerebral dura mater. The mediastinal, medial iliac and mesenteric lymph nodes were enlarged. There was a normal-appearing fetus of 4 months in the uterus.

Tissues were fixed in $10 \%$ buffered formalin, embedded in paraffin wax, and routinely processed for histological examination. Sections were stained with hematoxylin and eosin (HE) and naphthol AS-D chloroacetate esterase (CAE) [25]. In addition, selected sections were stained by the

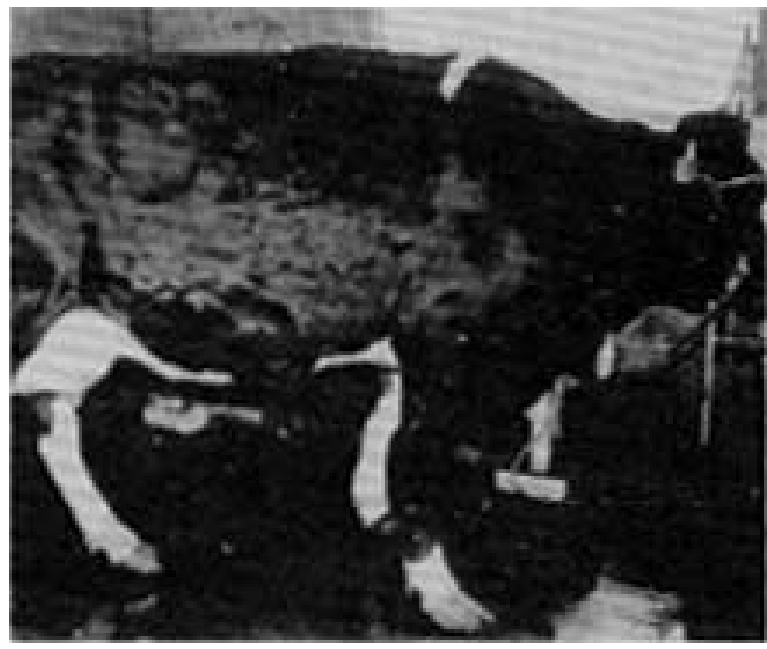

Fig. 1. In this photograph, multiple tumor nodules are discernible over the thorax and flank, and several are also seen on the shoulder. 


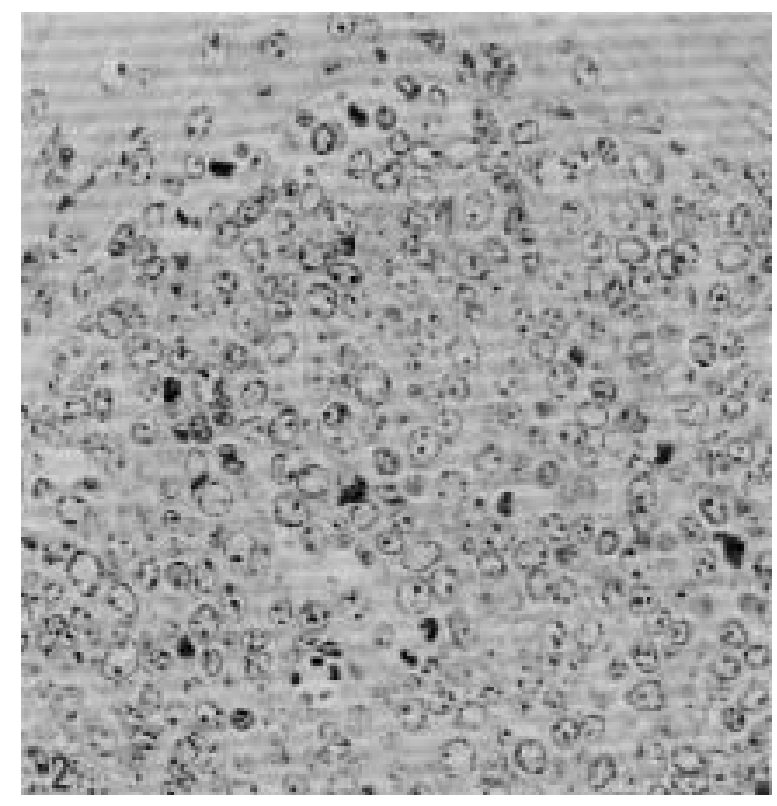

Fig. 2. The dermis is packed with tumor cells showing plentiful mitoses, but neoplastic invasion to the epidermis (top) is absent. HE. $\times 400$.

avidin-biotin-peroxidase complex immunoperoxidase technique (ABC-IP). The following monoclonal antibodies were used: anti-human myeloid/histiocyte antigen (MAC387), anti-human CD79a (HM57) (Dako, Glostrup, Denmark), and anti-major histocompatibility complex class II (MHC II) (H42A) (VMRD, Pullman, WA, U.S.A.). Antihuman CD3 polyclonal antibody (Dako) was also utilized. An immunoperoxidase staining kit (BioGenex Laboratories, San Ramon, U.S.A.) was used in the subsequent processes. For electron microscopy, small pieces taken from formalinfixed tissues were post-fixed in $1 \%$ osmium tetroxide, embedded in epoxy resin, stained with uranyl acetate and lead citrate, and examined by transmission electron microscopy (TEM). For immunohistochemical comparison, paraffin sections from a bovine cutaneous lymphoma were treated similarly.

Histologically, the subcutis and/or underlying musculature were involved with tumor in most skin lesions, but some lesions showed neoplastic growths in the dermis with the overlying epidermis remaining intact (Fig. 2). It was fairly rare to find neoplastic cells within the epidermis. The mediastinal mass consisted of neoplastic tissue with stromal fibrosis and widespread necrotic areas. The bone marrow was replaced by neoplastic tissue, but considerable numbers of normal-appearing hematopoietic cells were intermingled with neoplastic cells (Fig. 3). The lymph nodes examined were severely involved with tumor with capsular infiltration, but considerable parts of the cortex remained unchanged. The spleen was crowded with tumor cells, with slight extramedullary hematopoiesis and a few residual lymphatic

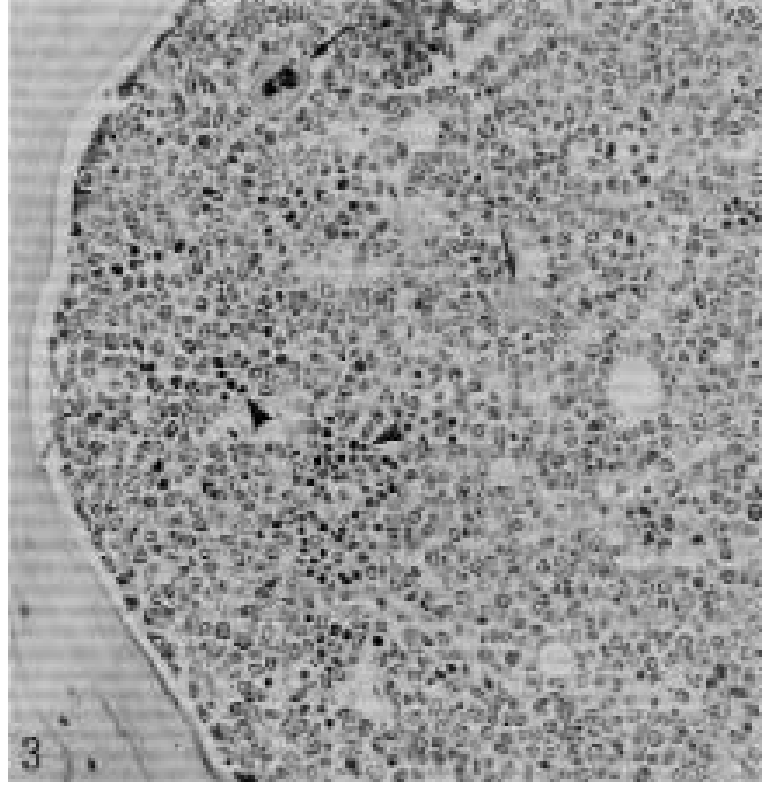

Fig. 3. The medullary cavity is filled with a solid sheet of tumor cells, but megakaryocytes (arrows) and rubricytes (arrowheads) survive. A bone trabecula is visible on the left. HE. $\times 200$.

follicles. The kidneys and tonsils were severely affected, and the former had extensive areas of necrosis. There were moderate neoplastic infiltrates in the ovaries. The other macroscopically visible nodules were composed of solid growths of neoplastic cells, and interstitial neoplastic infiltrates were also seen in the heart and liver. Appreciable numbers of neoplastic cells were detected in the alveolar capillaries and hepatic sinusoids.

The neoplastic cells were round in shape, $8-15 \mu \mathrm{m}$ in diameter, and larger cells predominated. The cells had large, rounded or ovoid nuclei occasionally with slight indentation, finely clumped chromatin, inconspicuous nucleoli, and small amounts of weakly basophilic cytoplasm. All neoplastic cells were negative for CAE. Mitotic figures were numerous.

Immunohistochemically, all markers were absent in the neoplastic cells, although CD3-positive lymphocytes containing irregularly contoured nuclei were sparsely distributed in the epidermis and external root sheath as well as in the dermis and subcutis (Fig. 4). The lymphoma cells in the skin form were positive for CD3 (Fig. 5), but not for the other markers.

Ultrastructurally, the nuclei were mildly irregular in many neoplastic cells, and contained abundant euchromatin. There were poorly developed organelles in the cytoplasm, but parallel strands of rough endoplasmic reticulum were detected in occasional cells, and a few scattered granules were seen in almost all cells (Fig. 6). Golgi complexes were rare and were accompanied with granules. Erythrophagia by tumor cells was exceedingly rare. 


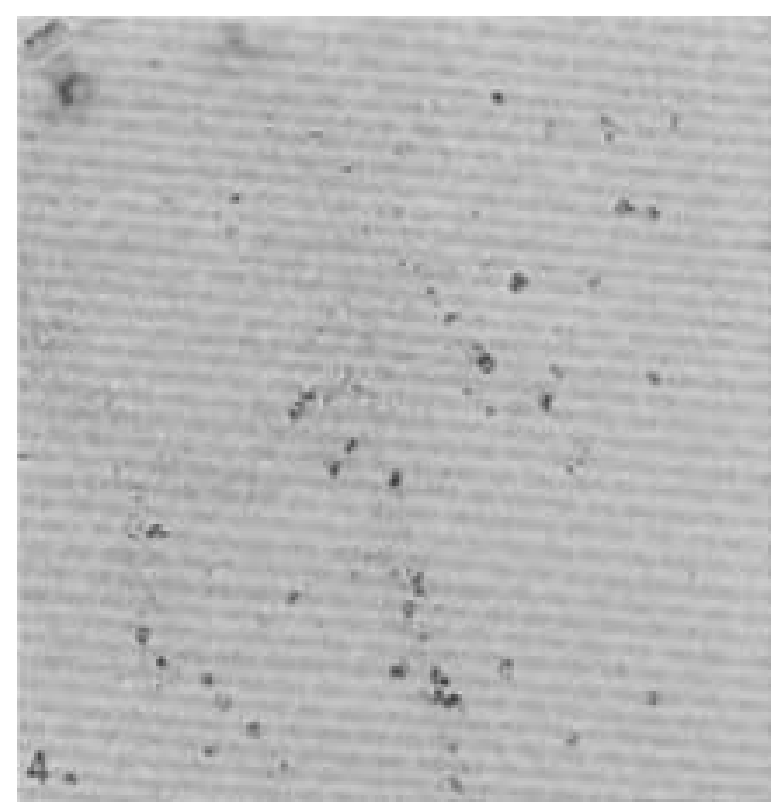

Fig. 4. There are several CD3-positive lymphocytes in the external root sheath and a few in the epidermis (top) and dermis. Neoplastic cells occupying the dermis are negative for CD3. ABC-IP. $\times 200$.

In the skin form of bovine lymphoma, the neoplastic cells characteristically involve the dermis with formation of Pautrier's microabscesses [7], but intraepidermal neoplastic cells were few in the tumor stage [11]. The thymic form is characterized by massive lymphoid infiltration of the thymus [20]. The present tumor, which had massive or nodular neoplastic lesions in the dermis and mediastinum, could not be differentiated distinctly from these lymphomas in HE preparations. The control case of skin lymphoma as well as thymic lymphoma cases $[1,26]$ exhibited CD3 positivity, and the presence of MHC II was demonstrated in enzootic [23] and sporadic B-cell [18] lymphomas. The present tumor had neither and was suggested to have originated from nonlymphoid tissue.

The neoplastic cells in our case did not have granulocyte markers as well as lymphocyte markers and MHC II, but their ultrastructural features corresponded to those of early promyelocytes [17] and did not to those of monocytes, such as many small phagocytic vesicles, phagosomes and fine villous projections [10]. Hence, a diagnosis of acute myeloblastic leukemia was made. A similar neoplasm consisting of early promyelocytes alone has been reported in a sow [9]. Myeloblastic leukemia without maturation is indistinguishable cytologically from lymphoblastic leukemia by routine histological methods [22]. However, the negative reactivity for CD3, CD79a and MHC II may be helpful to a distinction of some myeloproliferative disorders that are prone to be mistaken for lymphoid neoplasms, because CD3 is a pan-T marker and CD79a is usable as a pan-B marker in various animal species $[4,11,12,15,16$,

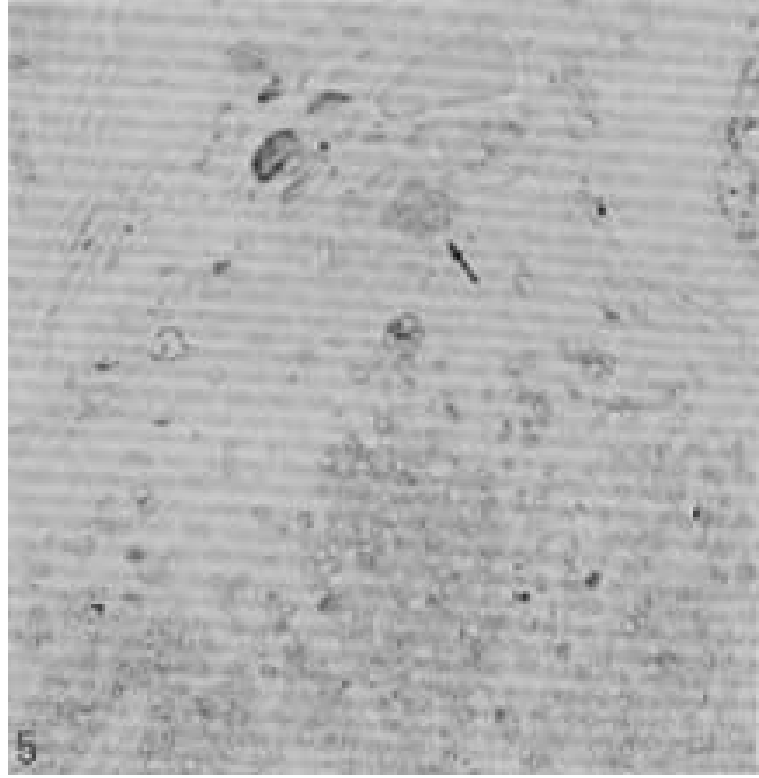

Fig. 5. The lesion of the skin form lymphoma is characterized by CD3-positive cells in the dermis (bottom). Arrow indicates intraepidermal neoplastic cells showing CD3 positivity. ABC-IP. $\times 200$.

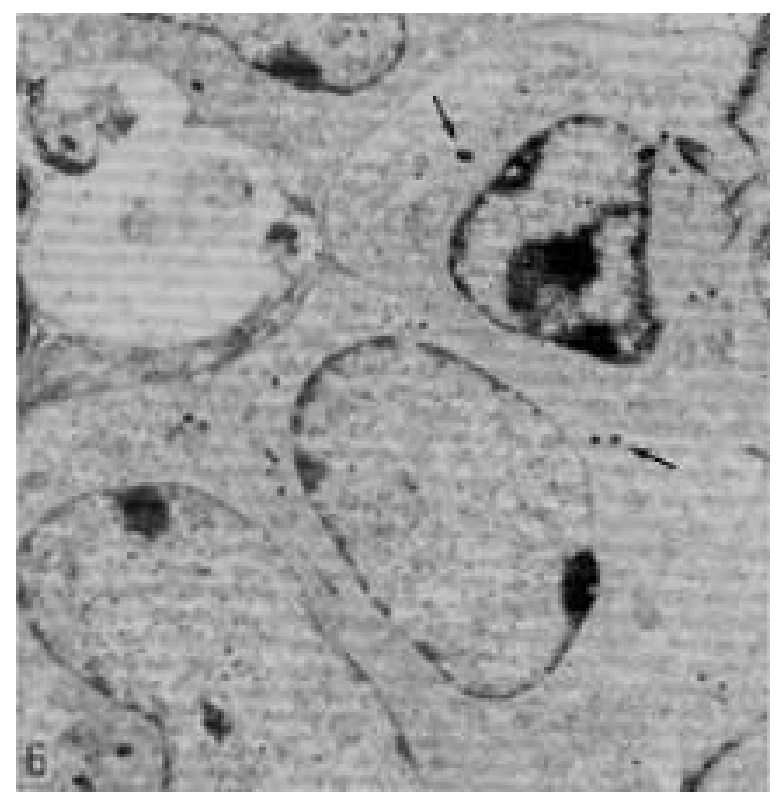

Fig. 6. In addition to a few scattered granules (arrows), the paucity of cytoplasmic organelles and abundance of euchromatin are characteristic of neoplastic cells. TEM. $\times$ 4,500 .

18, 19]. Although MHC II may be expressed by T-cells, macrophages and monocytes $[5,6]$, it was considered to be a B-cell marker in bovine and equine lymphomas [2, 15, 18, 23]. Some granulocyte markers did not make any 
contribution to our study, because these markers can detect late promyelocytes or more mature cells by light microscopy $[13,17]$

The antibodies to CD3 and CD79a used in the present study had broad species cross-reactivity, and were effective in paraffin sections in determing the phenotype of canine, feline and porcine lymphomas [4, 19]. In addition, the antiCD3 antibody was utilized for the identification of thymic T-cell lymphomas in cattle $[1,26]$ and of a simian T-cell lymphoma [16]. These antibodies are also available for the analysis of the inflammatory infiltrate in neoplastic or infectious diseases [13, 14].

Some myeloid leukemias may have massive neoplastic lesions, and are designated granulocytic sarcoma, myeloblastoma, or chloroma [3,9]. Although the presence of massive tumors seems to be an unusual feature of myeloproliferative disorders, there are not enough reports on such disorders to judge whether it is true or not in cattle. In a bovine acute erythremic myelosis, the most outstanding macroscopical feature was the formation of tumor nodules [24]. The capability of forming tumor masses in bovine myeloproliferative disorders needs to be explored further.

\section{REFERENCES}

1. Alexander, A. N., Constable, P. D., Meier, W. A., French, R. A., Morin, D. E., Lowry, J. E. and Hoffman, W. E. 1996. J. Vet. Intern. Med. 10: 275-278.

2. Asahina, M., Murakami, K., Ajito, T., Goryo, M. and Okada, K. 1994. J. Comp. Pathol. 111: 445-451.

3. Chaitin, B. A., Manning, J. T. and Ordóñez, N. G. 1984. Urology 23: 35-42.

4. Day, M. J. 1995. J. Comp. Pathol. 112: 79-86.

5. Day, M. J., Kyaw-Tanner, M., Silkstone, M. A., Lucke, V. M. and Robinson, W. F. 1999. J. Comp. Pathol. 120: 155167.

6. Freedman, A. S., Griffin, J. D. and Nadler, L. M. 1995. pp. 479-500. In: Diagnostic Immunopathology, 2nd ed. (Colvin, R. B., Bhan, A. K. and McCluskey R. T. eds.), Raven Press, New York

7. Ishino, S., Kadota, K., Nakagawa, M. and Yoshino, T. 1988. J. Vet. Med. A 35: 578-585.
8. Ishino, S., Kadota, K., Yoshino, T. and Yamamoto, H. 1990. J. Comp. Pathol. 103: 265-275.

9. Kadota, K., Akutsu, H., Saito, M., Kudo, T. and Gotoh, K. 1987. J. Comp. Pathol. 97: 401-406.

10. Mackey, L. J., Jarrett, W. F. H. and Wiseman, A. 1972. Res. Vet. Sci. 13: 287-289.

11. Okada, K., Yamaguchi, A., Ohshima, K., Numakunai, S., Itoh, H., Seimiya, Y. and Koyama, H. 1989. Vet. Pathol. 26: 136-143.

12. Pearson, G. R., Day, M. J., Main, D. and Pawade, J. 1999. J. Comp. Pathol. 120: 295-299.

13. Pérez, J., Ginel, P. J., Lucena, R., Hervás, J. and Mozos, E. 1997. J. Comp. Pathol. 117: 83-89.

14. Pérez, J., Mozos, E., Martín, M. P. and Day, M. J. 1999. J. Comp. Pathol. 121: 385-397.

15. Sasaki, Y., Ishiguro, N., Moriuchi, M., Shinagawa, M., Osame, S., Furuoka, H., Matsui, T., Asahina, M. and Okada, K. 1997. J. Comp. Pathol. 116: 13-20.

16. Sato, Y., Matsuura, S., Kadota, K. and Miyazawa, I. 1999. J. Vet. Med. Sci. 61: 49-52.

17. Takayama, H., Gejima, S., Honma, A., Ishikawa, Y. and Kadota, K. 1996. J. Comp. Pathol. 115: 95-101.

18. Tani, K., Asahina, M., Wu, D. L., Ajito, T., Murakami, K., Goryo, M., Aida, Y., Davis, W. C. and Okada, K. 1997. Vet. Immunol. Immunopathol. 55: 283-290.

19. Tanimoto, T. and Ohtsuki, Y. 1996. Am. J. Vet. Res. 57: 853859.

20. Theilen, G. H. and Madewell, B. R. 1987. pp. 408-430. In: Veterinary Cancer Medicine, 2nd ed. (Theilen, G. H. and Madewell, B. R. eds.), Lea \& Febiger, Philadelphia.

21. Trautwein, G. and Stöber, M. 1965. Zentralbl. Veterinaermed. A 12: 211-231.

22. Valli, V. E. O. 1993. pp. 101-265. In: Pathology of Domestic Animals, 4th ed. (Jubb, K. V. F. et al. eds.), San Diego, Academic Press.

23. Vernau, W., Jacobs, R. M., Valli, V. E. O. and Heeney, J. L. 1997. Vet. Pathol. 34: 222-225.

24. Watanabe, Y., Sekine, T., Yabe, M. and Kadota, K. 1998. J. Comp. Pathol. 119: 83-87.

25. Yam, L. T., Li, C. Y. and Crosby, W. H. 1971. Am. J. Clin. Pathol. 55: 283-290.

26. Yamazaki, Y., Ishikawa, Y., Shibahara, T., Kadota, K. and Ishino, S. 2000. Jpn. Agr. Res. Q. 34: in press. 